\title{
Evaluation of anionic and non-ionic surfactant performance for Montney shale gas hydraulic fracturing fluids
}

\author{
Sheau Chien Chee ${ }^{1,2}$ (1) $\cdot$ Belladonna Maulianda Hidayat ${ }^{1} \cdot$ Dzeti Farhah Mohshim $^{1} \cdot$ Zahidah Md Zain $^{2}$. \\ Ivy Ching Hsia Chai ${ }^{2} \cdot$ Norazleenawati Borhan $^{2} \cdot$ Hasnol Hady Ismail ${ }^{2} \cdot$ Matt Adam $^{3}$
}

Received: 28 August 2020 / Accepted: 8 March 2021 / Published online: 3 April 2021

(c) The Author(s) 2021

\begin{abstract}
Hydraulic fracturing is often used in unconventional shale reservoirs, and 50\%-95\% of the injected hydraulic fracturing fluid remains in the formation due to the capillary effect. This phenomenon has been observed in the Montney shale formation, Canada, where the flowback water recovery is generally less than $25 \%$. Surfactant is one of the hydraulic fracturing fluid additives for reducing surface tension and capillary forces to facilitate water flowback recovery. Surfactant loss due to adsorption by the reservoir rocks reduces the chemical's efficiency, and this causes water retention in the formation and reduces water flowback recovery. The compatibility of surfactant with reservoir rock is critical to minimize surfactant adsorption on the rock surface because this diminishes the primary function of the surfactant hydraulic fracturing fluid additive and to ensure cost-effectiveness. This study evaluates surfactant efficiency to improve flowback recovery for the Montney shale formation based on IFT, surface tension, and adsorption. This study evaluates surfactant performance and performs a fluid-fluid interaction experiment and fluid-rock compatibility investigation. Several commercial surfactants are screened for low interfacial tension and surface tension. Further analysis is carried out by evaluating the fluid-rock compatibility using the static soaking test at reservoir pressure and temperature. The pre-soaking and post-soaking test fluids were analyzed for water composition, liquid-liquid interfacial tension, surface tension, and $\mathrm{pH}$. Results showed that the selected surfactant is a critical determiner of the hydraulic fracturing fluid performance. SOLOTERRA 938 is an anionic surfactant that has good compatibility with Montney shale formation. Unlike other non-ionic surfactants, SOLOTERRA 938 retains the interfacial tension and surface tension after seven days of interaction with reservoir rock. The interfacial tension remained unchanged at $0.1 \mathrm{mN} / \mathrm{m}$. The surface tension decreased from 28.4 to $27.5 \mathrm{mN} / \mathrm{m}$ with air and from 21.7 to $20.8 \mathrm{mN} / \mathrm{m}$ with hydrocarbon because surfactant behavior changes with $\mathrm{pH}$ change. The surfactant concentration was measured using high-pressure liquid chromatography, and the loss was $12 \%$ after seven days of interaction with the reservoir rock (from 0.1 to $0.088 \mathrm{wt} \%$ ). The adsorption calculated based on the concentration volume showed a low value of between 0.43 and $0.97 \mathrm{mg} / \mathrm{g}$ rock.
\end{abstract}

Keywords Hydraulic fracturing fluids $\cdot$ Surfactant $\cdot$ Adsorption $\cdot$ Fluid-rock compatibility $\cdot$ Shale formation $\cdot$ Flowback water

Sheau Chien Chee

sheauchien@petronas.com.my

1 Petroleum Engineering Department, Universiti Teknologi PETRONAS, Persiaran UTP, 32610 Seri Iskandar, Perak, Malaysia

2 Petronas Research Sdn. Bhd. (PRSB), Kawasan Institusi Bangi, Kajang, 43000 Selangor, Malaysia

3 Petronas Canada, Fort St. John B.C. V1J 4M6, Canada

\section{Introduction}

The hydraulic fracturing technique was first used in 1947 in the Hugoton field, Kansas (Barati and Liang 2014). This technique is used in a low permeability reservoir to stimulate the reservoir by creating a conductive fracture network to facilitate the flow of fluids from the formation to the wellbore (Gharibi and Zoveidavianpoor 2015). A large volume of hydraulic fracturing fluids and proppant is pumped at high pressure and flow rate into the wellbore. The pumping fractured the formation when the wellbore pressure exceeded the fracture initiation pressure ( $\mathrm{Li}$ et al. 2013).

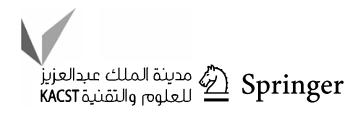


The hydraulic fracturing fluid injected into a shale gas reservoir consists of a hydraulic fracturing base fluid, proppant, and a mixture of low concentration chemical additives such as a surfactant, friction reducer, biocide, breaker, iron control, and scale inhibitor (Ferrer and Thurman 2015). The additive used and its concentration are dependent on the water and formation properties. Generally, hydraulic fracturing fluids consist of approximately around $99 \%$ mass of based fluid and proppant along with $1 \%$ mass chemical additives (Heyob et al. 2017). Figure 1 shows the hydraulic fracturing fluid additives.

Flowback water is one of the major concerns in a hydraulic fracturing operation. According to Chai et al. (2019), 50\% to $95 \%$ of the injected hydraulic fracturing fluid remained in the formation due to the capillary effect. The flowback water recovery ranges from 10 to $60 \%$ (Ghanbari and Dehghanpour 2016; Lu et al. 2018; Chai et al. 2019). The invading water can hinder hydrocarbon flow from the formation to the fractures due to water blockage and eventually impairs well productivity (Liang et al. 2020). Therefore, improved flowback recovery could enhance hydrocarbon production.

In field operations, water blockage is mitigated by shutting in the well or using surfactant as fracturing fluid additives. The well shut-in requires a long delay of hydrocarbon production, which could trigger clay swelling because of the reservoir rock exposure to fracturing fluid (Liang et al. 2020). Surfactant is used as fracturing fluid additive to reduce surface tension, lower the capillary forces to facilitate the recovery of the injected fluid, alter wettability, and reduce flow friction (Penny et al. 2005; Kaufman et al. 2008; Fichter et al. 2010; Ferrer and Thurman 2015; Mirchi et al. 2015; Yue et al. 2016; Chai et al. 2019; Rabie et at. 2019). It also reduces the interfacial tension between the injected hydraulic fracturing fluid and targeted formation. The hydraulic fracturing fluid requires a low interfacial tension to enter the induced hydraulic fracture and pre-existing natural fractures (Fichter et al. 2010).

He et al. (2015) compared the performance of nonsurfactant fluid, weakly emulsion surfactant fluid, and non-emulsion surfactant fluid in shale reservoirs. Weakly emulsion surfactant fluid yielded higher oil recovery relative to the non-surfactant fluid. The enhancement in surface clean-up efficiency and productivity is better relative to non-emulsion surfactant (He et al. 2015). Liang et al. (2020) reported the same observation where water trapping occurred in the no surfactant case.

The surfactant may lose its effectiveness due to adsorption and cause water retention in the formation matrix and reduces water flowback recovery (Fichter et al. 2010; Rabie et al. 2019). The hydraulic fracturing fluid that remained in the formation may cause water blockage and reduce well productivity (Rabie et al. 2019). Lu et al. (2018) reported that the main reason for hydraulic fracturing fluids retention in the formation and reduced water recovery was surfactant adsorption on the newly fractured micro-fracture surfaces. A more developed fracture network is more likely to retain water in the formation.

The compatibility of the chemicals and formation is critical for an effective hydraulic fracturing in reservoir stimulation. However, the interaction mechanism between the hydraulic fracturing fluid additive and reservoir rock is not fully understood because shale formations have different mineralogy and lithology. Each shale formation requires a specific hydraulic fracturing fluid additive recipe. According to Sun (2014), the design and selection of hydraulic fracturing fluid additives are dependent on the formation properties; however, there are no comprehensive criteria for hydraulic fracturing fluid selection (Sun 2014). The incompatibility between hydraulic fracturing fluids additives and reservoir rock can cause reservoir chemical damage.

Surfactants can be adsorbed on the formation surface and significantly alter the surface properties and cause phase trapping (Fichter et al. 2010). It can reduce the interfacial tension between water and the formation. Surfactants can also change the contact angle of the fluid with the rock surface and alter the change the fluid wettability of the formation. This facilitates recovery, especially in a tight gas reservoir (Penny, Pursley and Holcomb, 2005). Viscoelastic
Fig. 1 Hydraulic Fracturing Fluids Additives (Ferrer and Thurman, 2015)

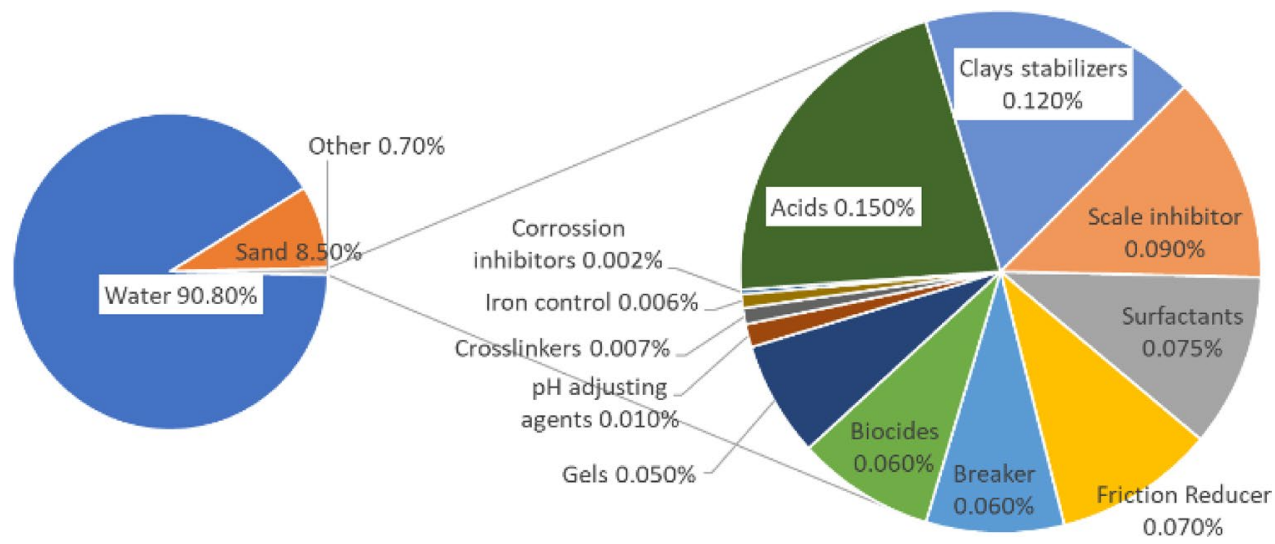


(VES) surfactant is generally used in hydraulic fracturing because its polymeric behavior reduces the friction during high-pressure fluid pumping.

Three types of viscoelastic surfactants are used in hydraulic fracturing fluids, cationic, anionic, and non-ionic surfactants. The cationic surfactants head carries a positive charge which may be permanent or only exists in a certain pH range (Rapp 2017). The adsorption of surfactants is influenced by the rock surface-fluid interface charge (Liu et al. 2004). Cationic surfactants are easily adsorbed and precipitated if the rock surface has a negative charge (Zhang et al. 2010). Anionic surfactant head carries a negative charge and exhibits high solubility in hydrocarbon but low solubility in aqueous solution (Fink 2013). The adsorption of anionic surfactant in shale or sandstone is low or even negligible due to repulsive electrostatic interaction with most natural surfaces since many natural surfaces are negatively charged under natural condition (Muherei and Junin 2009; Amirianshoja et al. 2013). Non-ionic surfactant head does not carry a charge (Belhaj et al. 2020). Muherei and Junin (2009) reported that non-ionic surfactants are more prone to adsorption on shale than sandstone because of hydrogen bonding and hydrophobic bonding. It was reported that the quantity of non-ionic surfactant adsorbed increased as the percentage of clay minerals increased (Amirianshoja et al. 2013).

Fluid adsorption and absorption influence the estimated hydrocarbon volumes that may occur in unconventional plays. Relative to conventional reservoirs, unconventional resources are characterized by small pores and large surface areas (Smith and Terracina 2006). Consequently, adsorption and absorption play more critical roles in unconventional resources than conventional reservoirs. Adsorption is the adhesion of molecules on solid surfaces. Absorption causes the molecules to form the bulk phase of the solid. However, in porous materials such as shale and kerogen, the difference between absorption and adsorption may not be apparent. It is difficult to determine whether molecules adhere to the pore wall or reside within the pore volume when the pore diameter is comparable to molecular diameters. This paper focuses on the concept of adsorption, although adsorption and absorption are not readily distinguishable in some cases.

\section{Materials and methodology}

\section{Recycle-produced water/flowback water and preparation of the testing fluid}

Recycle-produced water is the water from recovered flowback water that was collected in multiple ponds from the field as shown in Fig. 2. The water was delivered to laboratory using cold box to preserve and reduce composition change. The recycle-produced water was filtered with 100 mesh screens to mimic the field filtration level and the water composition, and the results are listed in Table 1 . The water was then mixed with different type of surfactant using magnetic stirrer for $1 \mathrm{~h}$. The solution was referred as surfactant hydraulic fracturing fluid.

\section{Surfactant}

Table 2 lists the 22 screen surfactants, which comprise 13 non-ionic, four anionic, two Zwitterionic, and two unknown head-type surfactants. The surfactants were obtained from chemical vendor suppliers. They have different purity range and were used as it is without any purification. The surfactants were screened for IFT $<0.1 \mathrm{mN} / \mathrm{m}$ and surface tension $<28 \mathrm{mN} / \mathrm{m}$. IFT and surface tension key performance was based on the trends identified from a chemical company survey. The screened surfactants selected for this study, SOLOTERRA 938, GlucoPure Wet, and Aspiro S2420X, are of the anionic and non-ionic types.
Fig. 2 Recycled-Produced Water as Received




Table 1 Water Composition

\begin{tabular}{|c|c|c|c|c|}
\hline No & Test Description & Method & Unit & Result \\
\hline 1 & Temperature & APHA $4500 \mathrm{H}+$, B & $\operatorname{deg} \mathrm{C}$ & 24.7 \\
\hline 2 & $\mathrm{pH}$ & APHA $4500 \mathrm{H}+$, B & - & 6.16 \\
\hline 3 & Density & ASTM 4052\# & $\mathrm{Kg} / \mathrm{m} 3$ & 1.11606 \\
\hline 4 & Conductivity & APHA 2510B\# & $\mu \mathrm{S} / \mathrm{cm}$ & 182,100 \\
\hline 5 & Salinity & APHA 2520B\# & $\mathrm{mg} / \mathrm{L}$ & over range \\
\hline 6 & Total Dissolved Solid & APHA 2540C & $\mathrm{mg} / \mathrm{L}$ & 136,900 \\
\hline 7 & Boron,B & APHA $3120 B$ & $\mathrm{mg} / \mathrm{L}$ & 13.76 \\
\hline 8 & Bismuth,Bi & APHA 3120B\# & $\mathrm{mg} / \mathrm{L}$ & $<0.001$ \\
\hline 9 & Lithium,Li & APHA $3120 B$ & $\mathrm{mg} / \mathrm{L}$ & 55 \\
\hline 10 & Manganese,Mn & APHA $3120 B$ & $\mathrm{mg} / \mathrm{L}$ & $<0.007$ \\
\hline 11 & Phosphorus,P & APHA 3120B\# & $\mathrm{mg} / \mathrm{L}$ & 0.49 \\
\hline 12 & Tin,Sn & APHA $3120 B$ & $\mathrm{mg} / \mathrm{L}$ & 0.228 \\
\hline 13 & Free Chlorine & НАCH 8167\# & $\mathrm{mg} / \mathrm{L}$ & 0.12 \\
\hline 14 & $\begin{array}{l}\text { Ammonia (as N) } \\
\text { Anion }\end{array}$ & НACH 8038/8155/8171\# & $\mathrm{mg} / \mathrm{L}$ & over range \\
\hline 15 & Sulfate & НАCH 8051\# & $\mathrm{mg} / \mathrm{L}$ & 1 \\
\hline 16 & Chloride & APHA 4500Cl-B & $\mathrm{mg} / \mathrm{L}$ & 102,805 \\
\hline 17 & $\begin{array}{l}\text { Bicarbonate, } \mathrm{HCO} 3- \\
\text { Total Anion } \\
\text { Cation }\end{array}$ & APHA 2320B & $\mathrm{mg} \mathrm{CaCO} 3 / \mathrm{L}$ & $\begin{array}{l}76.42 \\
102,882\end{array}$ \\
\hline 18 & Sodium,Na & APHA 3120B & $\mathrm{mg} / \mathrm{L}$ & 5122 \\
\hline 19 & Calcium,Ca & APHA 3120B & $\mathrm{mg} / \mathrm{L}$ & 7836 \\
\hline 20 & Magnesium,Mg & APHA 3120B & $\mathrm{mg} / \mathrm{L}$ & 837 \\
\hline 21 & Potassium,K & APHA $3120 B$ & $\mathrm{mg} / \mathrm{L}$ & 1215 \\
\hline 22 & Iron,Fe & APHA $3120 B$ & $\mathrm{mg} / \mathrm{L}$ & 0 \\
\hline 23 & Strontium,Sr & APHA 3120B & $\mathrm{mg} / \mathrm{L}$ & 1525 \\
\hline 24 & $\begin{array}{l}\text { Barium,Ba } \\
\text { Total Cation }\end{array}$ & APHA 3120B & $\mathrm{mg} / \mathrm{L}$ & $\begin{array}{l}241 \\
16,776\end{array}$ \\
\hline
\end{tabular}

\section{Shortlisted surfactant}

SOLOTERRA 938 SOLOTERRA 938 is fatty alcohol polyalkylene glycol ether acetic acid. It is an anionic surfactant and has an HLB of 12 that shows typical properties of nonionic surfactant in the acid environment. SOLOTERRA 938 is neutralized with alkali to form chemical corresponding to ether carboxylates, and it is $69 \%$ active, ether carboxylic acid, sodium ether carboxylate $\mathrm{Cn}-(\mathrm{PO}) \mathrm{z}-(\mathrm{EO}) \mathrm{y}-\mathrm{COONa}$ is expected to exhibit viscoelastic surfactant (VES) properties. The structure is shown in Fig. 3. As the characteristic of the brine system for fracturing fluid contains 150,000 TDS, it is ideal to use SOLOTERRA 938 as VES fracturing fluid without drag-reducing polymer at reservoir temperature.

GlucoPure wet GlucoPure ${ }^{\circledR}$ Wet is a low foam non-ionic surfactant with HLB of 13 with the active ingredient of $47 \%$ to $53 \%$ of sugar surfactant from the glucamide family, which is a non-EO solubilizer for hydrophobic $\mathrm{R}=\mathrm{C} 8 / 10$ methyl ester with higher wetting capacity. GlucoPure ${ }^{\circledR}$ Wet composition is $\mathrm{N}-\mathrm{C} 8 / 10$-acyl-N-methyl-glucamin, the structure as shown in Fig. 4. GlucoPure ${ }^{\circledR}$ Wet is miscible with all types of surfactants (anionic, non-ionic, cationic, and amphoteric). GlucoPure is chemically stable in acidic and alkaline media in the $\mathrm{pH}$ range of approximately 3 to 10 .

Aspiro S2420X Aspiro S2420X is an alkyl polyglycosides (APG) and the molecule structure as shown in Fig. 5. APG is a non-ionic surfactant that would make form sources from renewable raw materials or natural base stocks such as vegetable oils and starch or other carbohydrate-based materials (Nickel et al. 2007; Han et al. 2015).

\section{Hydrocarbon gas composition}

Table 3 presents the composition of the hydrocarbon gas used in this study. It is an average gas composition data from the study wells in Montney formation. 
Table 2 Twenty-two screened surfactants

\begin{tabular}{|c|c|c|c|}
\hline No & Surfactant Name & $\begin{array}{l}\text { Head Type (Non-ionic, } \\
\text { Cationic, Anionic, Zwit- } \\
\text { terionic) }\end{array}$ & Chemical Name \\
\hline 1 & SOLOTERRA 938 & Anionic & ethoxylated carboxylate, Isotridecanol, ethoxylated, carboxymethylated \\
\hline 2 & GlucoPure Wet & Non-ionic & Glucamine, N-C8/10-acyl-N-methyl-glucamin \\
\hline 3 & Aspiro S2420X & Non-ionic & Alkyl polyglycosides, D-Glucopyranose, oligomeric, C10-16 alkyl glycosides \\
\hline 4 & Lansurf OA14 & Non-ionic & Oleic Acid + 14EO (PEG600 Monooleate) \\
\hline 5 & Tergitol TM NP-10 & Non-ionic & $\begin{array}{l}\text { Poly(oxy-1,2-ethanediyl), alpha-(4-nonylphenyl)-omega-hydroxy-, Polyethyl- } \\
\text { ene glycol, Dinonylphenyl polyoxyethylene, } 10 \text { EO mole }\end{array}$ \\
\hline 6 & Tergitol TM NP-9 & Non-ionic & $\begin{array}{l}\text { Poly(oxy-1,2-ethanediyl), alpha-(4-nonylphenyl)-omega-hydroxy-, Polyethyl- } \\
\text { ene glycol, Dinonylphenyl polyoxyethylene, } 9 \text { EO mole }\end{array}$ \\
\hline 7 & Genapol EP 2552 & Non-ionic & C12-15 OXO alcohol PO-EO adduct \\
\hline 8 & SOLOTERRA 970 & Anionic & Isotrideccan-1-01, ethoxylated, propoxylated, carboxymethylated \\
\hline 9 & SOLOTERRA 963 & Anionic & Alcohols, C16-17 branched and linear, ethoxylated, carboxymethylated \\
\hline 10 & Tergitol TM NP-7.5 & Non-ionic & $\begin{array}{l}\text { Poly(oxy-1,2-ethanediyl), alpha-(4-nonylphenyl)-omega-hydroxy-, Polyethyl- } \\
\text { ene glycol, Dinonylphenyl polyoxyethylene, } 7.5 \text { EO mole }\end{array}$ \\
\hline 11 & Euroquat PK47 & Zwitterionic & Cocamidopropyl betaine based on palm kernel oil \\
\hline 12 & NOVEL® TDA-3 Ethoxylate & Non-ionic & $\begin{array}{l}\text { Ethoxylated Alcohol, Trideceth-3. Derived from branched C13 alcohol and } \\
\text { ethoxylated to an average of } 3 \text { mol of ethylene oxide }\end{array}$ \\
\hline 13 & Plexsurf 200E & & Not available \\
\hline 14 & CRS 2080 & & Not available \\
\hline 15 & Genapol EP 0244 & Non-ionic & C10-C12 alcohol EO-PO adduct \\
\hline 16 & Tergitol TM NP-6 & Non-ionic & $\begin{array}{l}\text { Poly(oxy-1,2-ethanediyl), alpha-(4-nonylphenyl)-omega-hydroxy-, Polyethyl- } \\
\text { ene glycol, Dinonylphenyl polyoxyethylene, } 6 \text { EO mole }\end{array}$ \\
\hline 17 & Euroquat $\mathrm{HC} 47 \mathrm{VG}$ & Zwitterionic & Cocamidopropyl betaine based on coconut oil \\
\hline 18 & Tergitol Tм NP-8 & Non-ionic & $\begin{array}{l}\text { Poly(oxy-1,2-ethanediyl), alpha-(4-nonylphenyl)-omega-hydroxy-, Polyethyl- } \\
\text { ene glycol, Dinonylphenyl polyoxyethylene, } 8 \text { EO mole }\end{array}$ \\
\hline 19 & Tergitol TM NP-4 & Non-ionic & $\begin{array}{l}\text { Poly(oxy-1,2-ethanediyl), alpha-(4-nonylphenyl)-omega-hydroxy-, Polyethyl- } \\
\text { ene glycol, Dinonylphenyl polyoxyethylene, } 4 \text { EO mole }\end{array}$ \\
\hline 20 & Lansurf OA10 & Non-ionic & Oleic Acid + 10EO (PEG400 Monooleate) \\
\hline 21 & Tergitol TM NP-40 & Non-ionic & $\begin{array}{l}\text { Poly(oxy-1,2-ethanediyl), alpha-(4-nonylphenyl)-omega-hydroxy-, water, } \\
\text { Polyethylene glycol, Dinonylphenyl polyoxyethylene, } 40 \text { EO mole }\end{array}$ \\
\hline 22 & SOLOTERRA 961 & Anionic & Alcohols, C16-18, ethoxylated, propoxylated, carboxymethylated \\
\hline
\end{tabular}

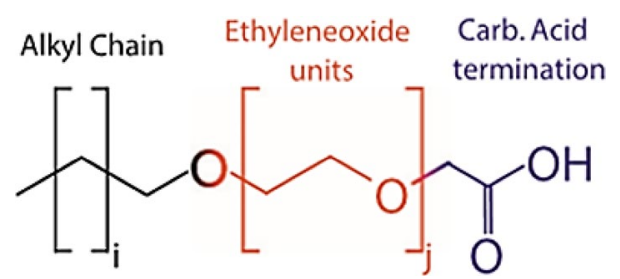

Fig. 3 Schematic Representation the Chemical Formula of Polyethylene Alkyl Ether Carboxylic Acids Composed of a Hydrophobic, Alkyl Chain, Hydrophilic Ethylene Oxide Units and Terminated by a Carboxy-Methyl Unit (Chiappisi, 2017)<smiles>CCCCCCCCCCCC(=O)N(C)CC(O)C(O)C(O)C(O)CO</smiles>

Fig. 4 Structure of Glucamine molecule

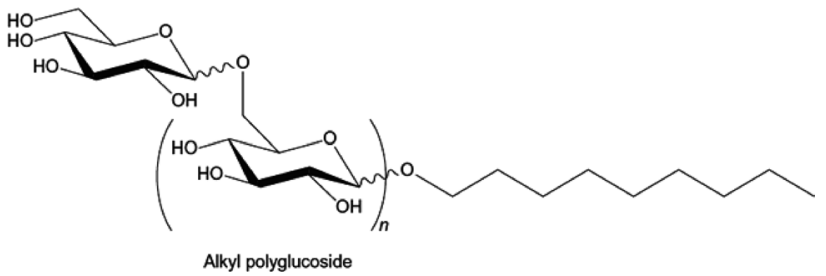

Fig. 5 Structure of APG molecule

\section{Preparation and characterization of core samples}

This study investigated the interaction between hydraulic fracturing fluids and three types of lithofacies. Table 4 lists the nine samples of 1-inch diameter used in the testing. The core samples are the native core samples obtained from Montney formation. The air method was employed to plug the core samples to minimize sample damage that may occur 
Table 3 Hydrocarbon Gas Composition

\begin{tabular}{llc}
\hline Component & & Mole $\%$ \\
\hline Hydrogen & H2 & 0.07 \\
\hline Nitrogen & $\mathrm{N} 2$ & 0.17 \\
Carbon Dioxide & $\mathrm{CO} 2$ & 0.23 \\
Methane & $\mathrm{C} 1$ & 85.91 \\
Ethane & $\mathrm{C} 2$ & 8.57 \\
Propane & $\mathrm{C} 3$ & 2.76 \\
i-Butane & iC4 & 0.64 \\
n-Butane & nC4 & 0.77 \\
i-Pentane & iC5 & 0.28 \\
n-Pentane & nC5 & 0.21 \\
Hexane & C6 & 0.20 \\
Heptane & C7 & 0.19 \\
\hline
\end{tabular}

Table 4 Core Availability by Lithofacies

\begin{tabular}{ll}
\hline Lithofacies & $\begin{array}{l}\text { Number of core } \\
\text { samples for Soaking } \\
\text { Test }\end{array}$ \\
\hline 1 Sandy F-C Siltstone to Silty VF Sandstone & 3 \\
2 Bituminous F-C Siltstone & 3 \\
3 Bituminous F-M Siltstone & 3 \\
Total Number of Samples & 9 \\
\hline
\end{tabular}

due to the high clay content in shale. The core sample selection was based on the CT scan images and the supporting data from X-ray diffraction (XRD) and scanning electron microscopy (SEM). The samples were taken from a depth between 1999.87 and $2175.7 \mathrm{~m}$. The sample permeability ranges from 14.71 to 1198.71 nanodarcy, and the porosity ranges from $0.12 \%$ to $6.97 \%$. The core sample diameter ranges from $2.53 \mathrm{~cm}$ to $2.57 \mathrm{~cm}$, and the core length ranges between $5.74 \mathrm{~cm}$ and $8.83 \mathrm{~cm}$.

\section{Core CT scan}

Core CT scans measures the radiodensity of the core material at a sub-millimeter resolution. The dataset is presented as static 2D images or video scans (Hall and Govert 2016). CT enables detection and evaluation of internal geological structures such as bedding planes, fractures and nodules, lithological changes, and bulk density. This method is widely used in the industry for core selection since it provides insight into the core without exposing the core surface.

The CT scan used in this study is Philips Ingenuity CT Scan (serial number: 336233) as shown in Fig. 6. It is a computerized tomography (CT) or computerized axial tomography (CAT) scan that combines the data from several

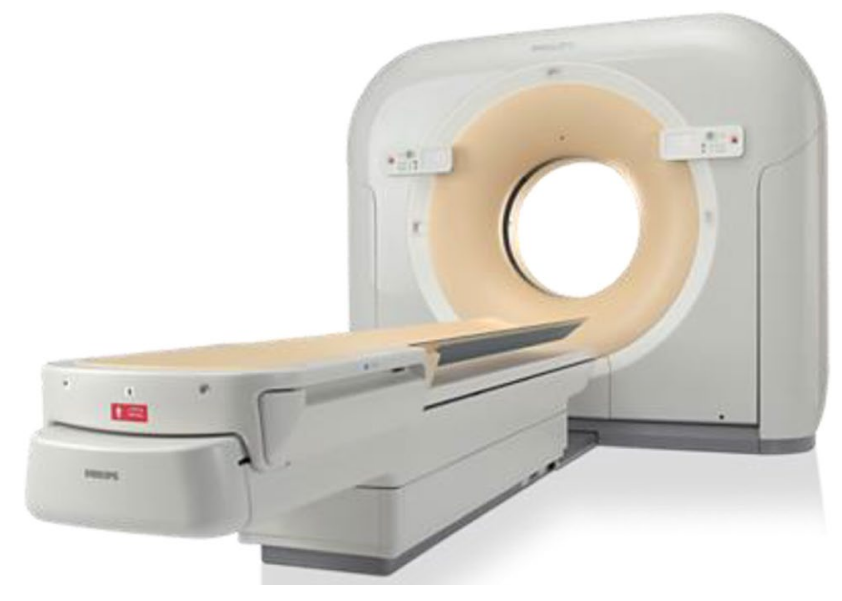

Fig. 6 Philip CT scan



Fig. 7 Shimadzu X-ray Diffractometer Machine

$\mathrm{X}$-rays to produce a detailed image of the structures inside the sample.

The nine core plug samples were subjected to core plug CT scan to evaluate the core state (heterogeneity, nodules, fractured, etc.). The results were used to select the core samples for routine analysis and special tests and avoid the selection of unsuitable sections. The CT scan was carried out with two axial scans and two transverse scans.

\section{X-ray diffraction (XRD)}

This study used X-ray diffraction (XRD) spectroscopy to analyze the rock samples from the Montney shale formation and determine their mineral composition. Figure 7 shows a 
Shimadzu X-ray diffractometer machine (model XRD-700) used to perform the analysis.

The sample for the bulk rock XRD analysis was a representative portion of the sample, and about $10 \mathrm{~g}$ of the rock is used in routine analysis. The samples do not require preservation other than keeping them in ambient condition after sampling. The sample selected for XRD was dried, disaggregated, and cleaned of hydrocarbons using chloroform and methanol. The sample was gently ground using ceramic mortar and pestle to obtain a powder with 5-10 microns particle size. The powdered sample was packed in an aluminum holder and X-rayed from 2 thetas $(\theta)$ of 2 to 65 degrees. The mineral (i.e., peak) identification of the analyzed sample was performed at d-spacing of the detected peak in the $\mathrm{X}$-ray diffractogram of the sample. The semi-quantitative method established by Huggett (1992) was employed to analyze the bulk mineralogical content (Huggett 1992). The peak intensity (either area count or height) for each mineral was multiplied with a specific factor, which was derived by measuring peak intensities of the standard minerals from known mixtures, and the quantification was derived using the Siroquant software.

\section{High-pressure mercury injection}

The AutoPore IV Series Automated Mercury Porosimeter was used to inject the high-pressure mercury. The mercury injection test was performed on trimmed ends samples. Mercury was injected at incrementally increasing pressure of up to $60,000 \mathrm{psi}$. The data were used to generate capillary pressure $(\mathrm{Pc})$ curves and pore (throat) size distribution data. The high-pressure data reveal the extent of the microporosity.

\section{Three point bending}

Before the soaking test, the core samples were fractured using a three-point bending apparatus to obtain a larger contact surface and maximize the fluid-rock interaction. A minimal load was applied to the core samples to obtain a straight-line fracture across the core sample diameter. Figure 8 shows the three-point bending apparatus and its accessories, including the cutting blade and sample holder.

The cutting blade and sample holder are specially fabricated for this study, where the thinner cutting blade produced a thinner slick fracture. The holder prevents the samples from fracturing in other directions.

\section{Surface tension measurement}

This study used the pendant drop tensiometer (Vinci IFT700) to measure the gas-liquid surface tension. It is used to measure the IFT with values greater than $10^{-3} \mathrm{~N} / \mathrm{m}$. The measurement principle was based on the fluid droplet in a gas environment, where the fluid and gas are immiscible (Stauffer 1965; Moiré et al. 2016). A fluid droplet is attached to the end of a needle, and its profile is influenced by the IFT and density difference between the fluid and gas. A numerical analysis of the droplet profile and the Young-Laplace equations is used to determine the IFT (Moiré et al. 2016).
Fig. 8 Three-point Bending Testing Apparatus and Its Accessories

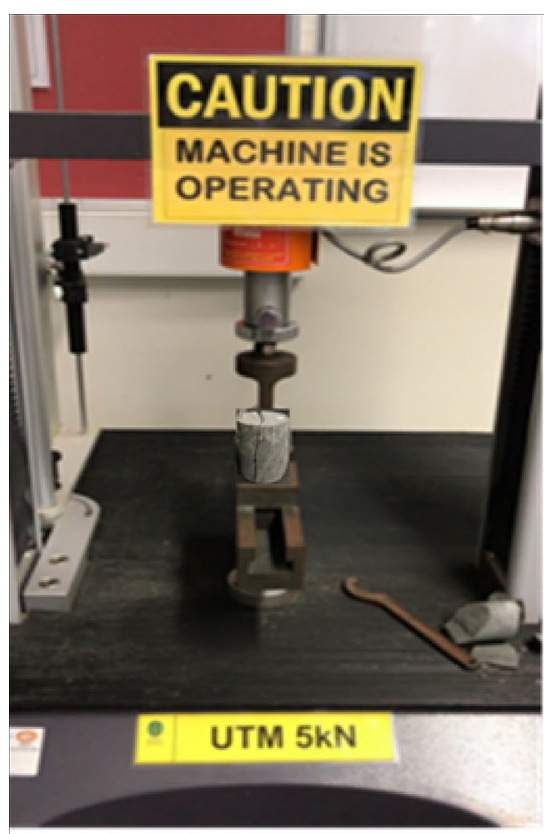

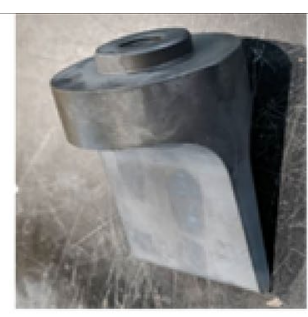

Cutting blade

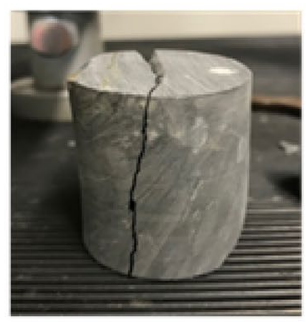

fracture samples

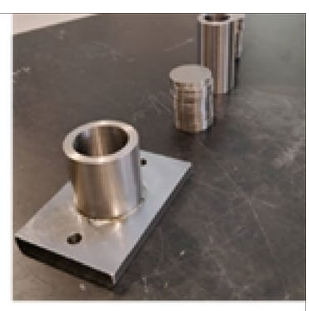

Samples Holder
3-Point Bending Apparatus 


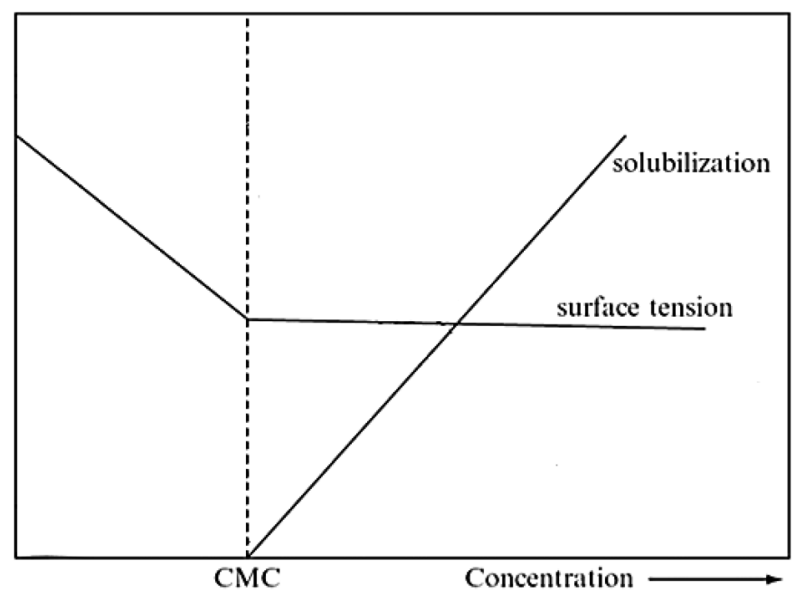

Fig. 9 Schematic representation of the concentration dependence of surface tension and solubilization properties for solutions of surfactant (Tadros, 2010)

The measurement was taken at room condition of $22^{\circ} \mathrm{C}$ and 14.7 psia.

The surface tension technique was used to determine the critical micelle concentration (CMC) values. The surface tension values were plotted against surfactant concentrations to obtain the CMC, which is the lowest surface tension reading, and remains relatively constant after that point, as shown in Fig. 9.

The CMC of each surfactant varies and is influenced by several factors (Lu 2016).

- An increase in the surfactant's alkyl chain length will result in a considerably lower CMC.

- Generally, non-ionic surfactants have lower CMCs than the ionic surfactants with the same hydrophobic chain.

- Cationic surfactants typically have slightly higher CMCs than anionic surfactants.

GlucoPure ${ }^{\circledR}$ Wet is a low-foam non-ionic sugar-based surfactant with a chemical formula N-C8/10-acyl-N-methylglucamine. Its CMC is $0.0068 \mathrm{wt} \%$ at a temperature of $70{ }^{\circ} \mathrm{C}$ with methanol and water solution (Warwel et al. 2001). Aspiro S2420X is an APG-type non-ionic surfactant and has a CMC of $0.056 \mathrm{wt} \%$ for carbon chain C8 to $\mathrm{C} 10$ at $60{ }^{\circ} \mathrm{C}$ with distilled water (Nickel et al. 2007; Sulek and Wasilewski 2009).

The CMC for SOLOTERRA 938 was measured at eight different concentrations of $0.025,0.05,0.1,0.2,0.3,0.4$ and $0.5 \mathrm{wt} \%$. Figure 10 shows that the CMC of SOLOTERRA 938 is at $0.1 \mathrm{wt} \%$.

The CMCs for the surfactants range from 0.0068 to 0.1 wt\%. SOLOTERRA 938 was measured using Montney

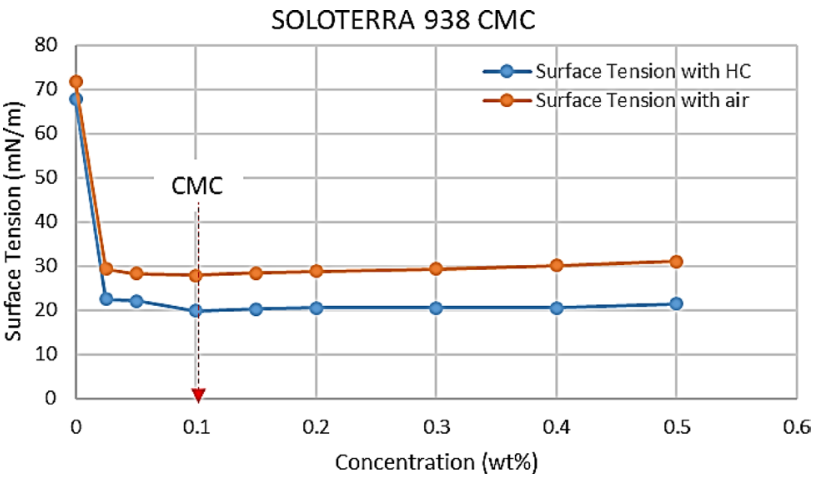

Fig. 10 SOLOTERRA 938 Surface Tension with Concentration Relationship

fluids and had the highest CMC. All soaking test surfactant was tested at $0.1 \mathrm{wt} \%$ concentration.

Therefore, the CMC value for 3 surfactants ranges from 0.0068 to $0.1 \mathrm{wt} \%$. SOLOTERRA 938 was measured using Montney fluids, and given the highest CMC, all soaking test surfactant was tested at the concentration of $0.1 \mathrm{wt} \%$.

\section{Interfacial tension measurement}

The equipment for measuring IFT is the spinning drop tension meter (Grace GM6500). The target IFT value for surfactant-based hydraulic fracturing fluids is $0.1 \mathrm{mN} / \mathrm{m}$ (millinewton/meter) and below. The measurement was taken using hydraulic fracturing fluid and condensate so that the condensate oil droplet can be easily displaced because of the resulting high capillary number (Wu et al. 2010). The measurement was taken at ambient temperature and pressure because the sample behavior is sensitive to pressure and temperature changes. This method involved injecting a droplet of Fluid 2 into a capillary tube filled with Fluid 1 (Vonnegut 1942; Moiré et al. 2016). The capillary rotation causes the injected droplet to elongate. The droplet profile is the result of the equilibrium between the centrifugal and interfacial forces. As with the pendant drop method, the IFT was determined using the numerical analysis of the droplet profile and the Young-Laplace equations. For an IFT less than $10^{-5} \mathrm{~N} / \mathrm{m}$, the measurement uncertainty may exceed $100 \%$ (Moiré et al. 2016).

\section{pH measurement}

The basic principle of electrometric pH measurement is determining hydrogen ions activity. The potentiometric measurement employed the standard hydrogen electrode and a reference electrode. The $\mathrm{pH}$ meter used in this study is from Mettler Toledo (seven compact model). 


\section{Soaking test}

The fluid-rock interaction was initiated by performing the soaking test at reservoir pressure and temperature. Soaking is similar to leaving the well shut-in for an extended period after the flowback stage before putting it on production (Yaich et al. 2015). However, there is some concern with leaving hydraulic fracturing fluid in the well as it could cause formation damage. Yaich et al. (2015) investigated the impact of extended shut-in in different areas of the Marcellus shale and found that the well shut-in after flowback resulted in potentially higher initial gas flow rate and improved performance.

The soaking test was performed on the core samples from different lithofacies of the siltstone formation. The fluid and core samples weights in the soaking experiment were adapted from the soaking experiment for a limestone reservoir with some modification, such as the apparatus used. The core sample weight to hydraulic fracturing fluid weight ratio for the test is 1:4 (Sterpenich et al. 2009). The samples were soaked for seven days at reservoir pressure and temperature. A seven-day soaking is a minimum period before a hydraulic fracturing well start to flowback in Montney formation. Figure 11 shows that the system was pressurized using hydrocarbon gas to mimic the reservoir condition. A laboratory soaking experiment should represent the natural systems as much as possible (Sterpenich et al. 2009).

Analysis of water chemistry was carried out before and after soaking. After the soaking, the fluid was analyzed for water chemistry, and the core sample was analyzed using the high-pressure mercury injection (HPMI) (Fig. 12). The pre-soaking and post-soaking measurements include:
1. Liquid-liquid interfacial tension (IFT).

2. Surface tension.

3. $\mathrm{pH}$.

4. Surfactant concentration and adsorption.

\section{Surfactant concentration and adsorption}

Surfactant concentration was measured using the high-performance liquid chromatography (HPLC) analysis. HPLC is a component separation technique using column chromatography that pumps a sample in a mobile phase (solvent) at high pressure through a column with a stationary phase. HPLC is used to determine the concentration of active components such as ether carboxylate, alkyl glucamine, and ethoxylated nonylphenol before and after the soaking tests. HPLC (Agilent 1100 Series, Agilent Technologies, USA) is equipped with an evaporative light scattering emission (ELSD) detector. Different reversed-phase columns were employed to separate the active components depending on the active ingredients of the materials. The mobile phase is methanol:water $(\mathrm{v} / \mathrm{v})$ in gradient flow. The column temperature differs depending on the surfactant type, and the injected volume is $5 \mu \mathrm{L}$. The external calibration based on the peak areas was used to calculate active ingredient concentration.

Fluid adsorption and absorption influence the estimated hydrocarbon volumes that may occur in unconventional plays. Unconventional resources are characterized by small pores and large surface areas (Smith and Terracina 2006), and adsorption and absorption play more critical roles in unconventional resources. Adsorption is the adhesion of molecules to solid surfaces. Absorption causes the formation
Fig. 11 Soaking test schematic diagram

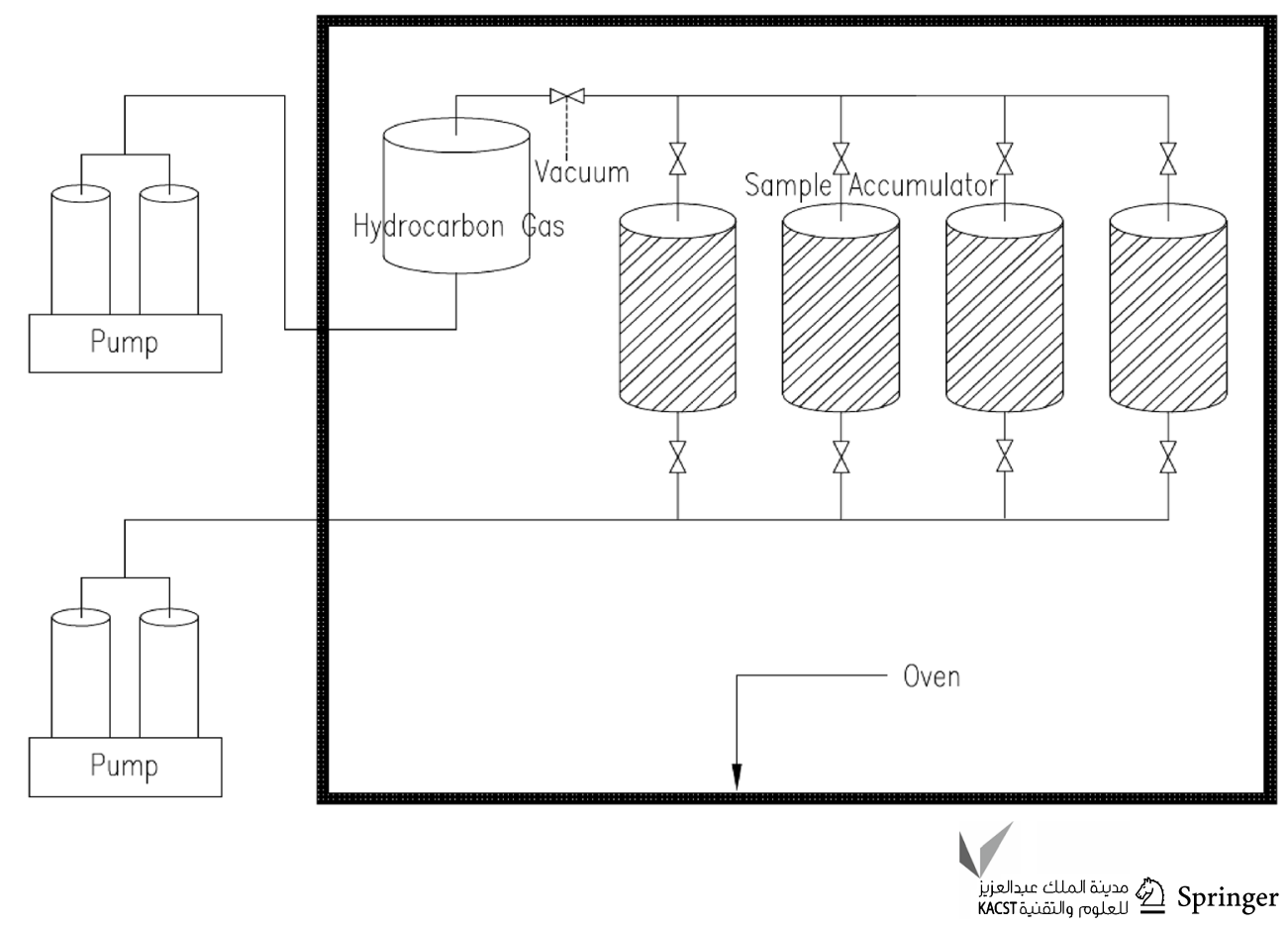




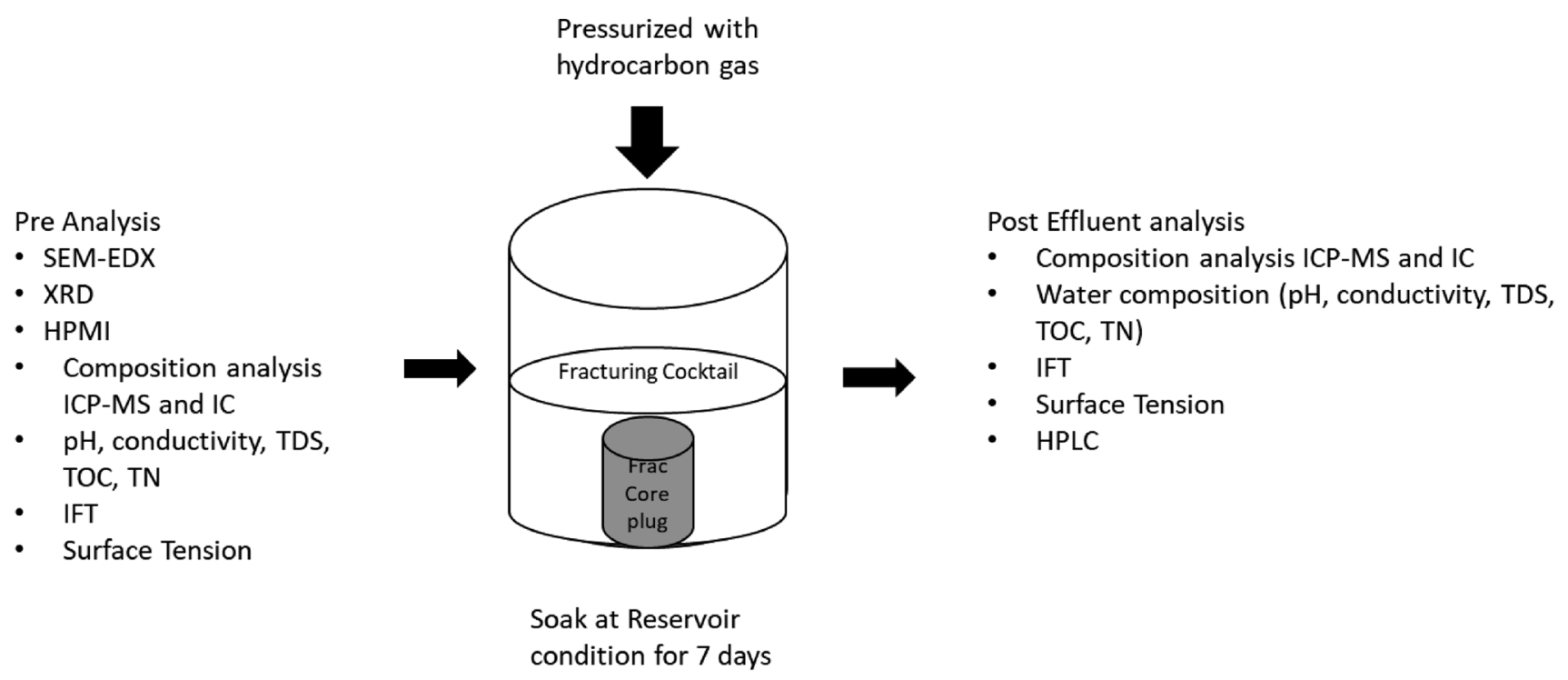

Fig. 12 Soaking test analysis workflow

of molecules in the bulk phase of the solid. However, the difference between absorption and adsorption may not be apparent in porous materials such as shale and kerogen. When pore diameters are comparable to molecular diameters, it is difficult to determine whether the molecules adhere to the pore wall or are within the pore volume. This section focuses on the concept of adsorption, although adsorption and absorption are not readily distinguishable in some cases.

A static adsorption experiment was carried out to quantify the loss of surfactant by adsorption onto a rock under simulated (static) conditions. Rock clay content, rock mineralogy, temperature, and salinity affect surfactant adsorption on rock surfaces. The static adsorption test used the fluid from the soaking test, and the test was performed on different lithofacies of siltstone reservoir in Montney formation.

The chemical adsorption unit in the laboratory is reported as mass of the chemical adsorbed per unit mass of rock $(\mathrm{mg} / \mathrm{g})$, as per the following equation. and selected for the soaking test. Figure 13 lists the selected sample based on the CT scan image.

XRD results were used to determine the total clay content of samples. Clays information is a necessary prerequisite for assessing the effectiveness of surfactant, especially in investigating the adsorption of surfactants (Amirianshoja et al. 2013). Figure 14 shows the XRD results, where the samples comprise primarily of quartz $(38.6 \%-58.6 \%)$, plagioclase $(13.4 \%-20.7 \%)$, k-feldspar $(0 \%-11.9 \%)$, calcite $(6.9 \%-12.2 \%)$, dolomite $(6.3 \%-16.6 \%)$, and total clay $(1.3 \%-8.37 \%)$. The total clay content comprises of illites $(96.4 \%-98.8 \%)$, kaolinite $(0.1 \%-1.6 \%)$, Chloride $(0-1.7 \%)$, mixed layer $(0.5 \%-0.9 \%)$, and smectite $(0.3 \%$ $0.6 \%)$. The measured ranges were broad and include different formation classes and depths. As reported by Amirianshoja et al. (2013), the anionic surfactant was less adsorbed and normally negligible in most cases comparing with the non-ionic surfactant. The rank order of adsorption for non-

Adsorption, $\mathrm{mg} / \mathrm{g}=\frac{[\text { Initial Conc }- \text { Final Conc. }](\mathrm{mg} / \mathrm{L}) \times \text { Vol.of Solution }(\mathrm{L})}{\text { Dry weight of rock }(\mathrm{g})}$

where Conc is concentration, $\mathrm{mg} / \mathrm{L}$, and Vol is volume, $\mathrm{L}$

\section{Results and discussion}

\section{Shale properties and characterization}

The cores were imaged using CT scan to enable evaluation of core state (heterogeneity, nodules, fractured, etc.) ionic surfactant is illite $>$ kaolinite (Amirianshoja et al. 2013). The adsorption due to kaolinite might be negligible since the total clay content is small.

Javaheri et al. (2018) investigated the plugs cored from a well in the Gordondale area, which only covers the upper and lower Montney formations with a depth of $2100-2200 \mathrm{~m}$. The XRD results showed the samples are made up of quartz (40\%45\%), k-feldspar (9\%-15\%), plagioclase (10\%-16\%), dolomite (14\%-22\%), and clay (9\%-14\%) (Javaheri et al. 2018). 




Sample ID: 27

Depth: 1999.87m

Lithofacies: 1 Sandy

F-C Siltstone to Silty

VF Sandstone

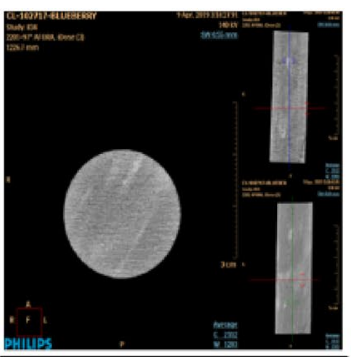

Sample ID: 26

Depth: $2000.9 \mathrm{~m}$

Lithofacies: 1 Sandy

F-C Siltstone to Silty

VF Sandstone

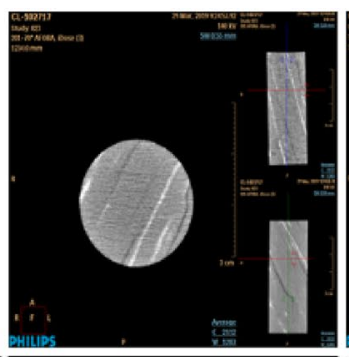

Sample ID: 53

Depth: $2007.9 \mathrm{~m}$

Lithofacies: 1 Sandy

F-C Siltstone to Silty

VF Sandstone



Sample ID: 20

Depth: $2071.9 \mathrm{~m}$

Lithofacies: 2

Bituminous F-C Siltstone

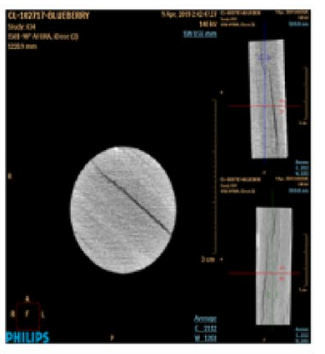

Sample ID: 19

Depth: $2072.04 \mathrm{~m}$

Lithofacies: 2

Bituminous F-C

Siltsone

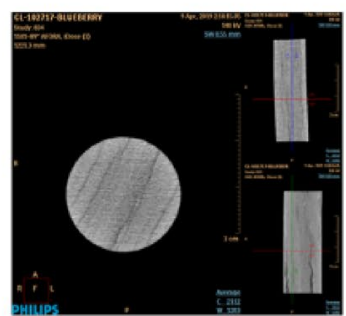

Sample ID:9 Depth: $2087.75 \mathrm{~m}$ Lithofacies: 2

Bituminous F-C

Siltsone

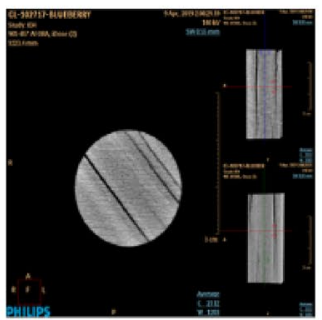

Sample ID: 5 Depth: $2175.7 \mathrm{~m}$ Lithofacies: 3

Bituminous F-M

Siltstone



Sample ID: 37 Depth: $2039.89 \mathrm{~m}$ Lithofacies: 3

Bituminous F-M Siltstone

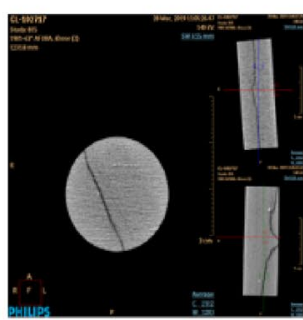

Sample ID: 36 Depth: $2045.26 \mathrm{~m}$ Lithofacies: 3

Bituminous F-M Siltstone

Fig. 13 CT Scan Images of Selected Core Samples for Surfactant Performance Fluid-rock Interaction

Fig. 14 XRD Results



Figure 15 shows the capillary pressure and pore throat size distribution. Based on the capillary pressure curve and pore size distribution, lithofacies 3 is tighter than lithofacies
1 and 2. The pore size distribution for all lithofacies showed that the Montney shale samples have micropore throat radius. 
Lithofacies 1 Capillary pressure

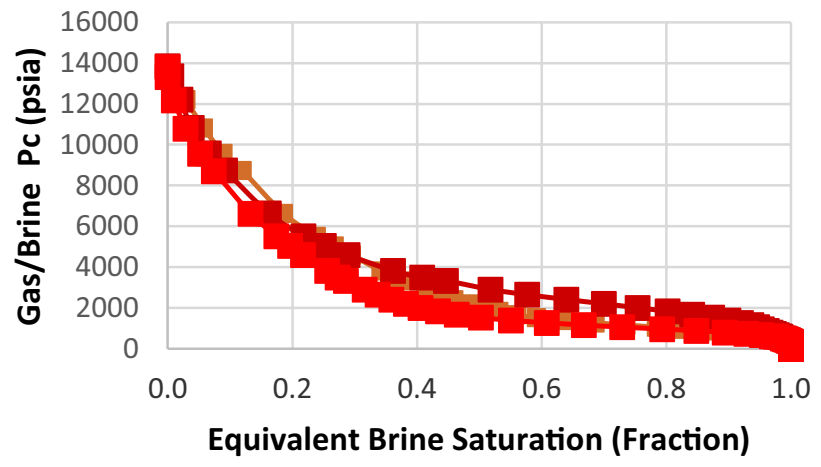

Lithofacies 2 Capillary pressure

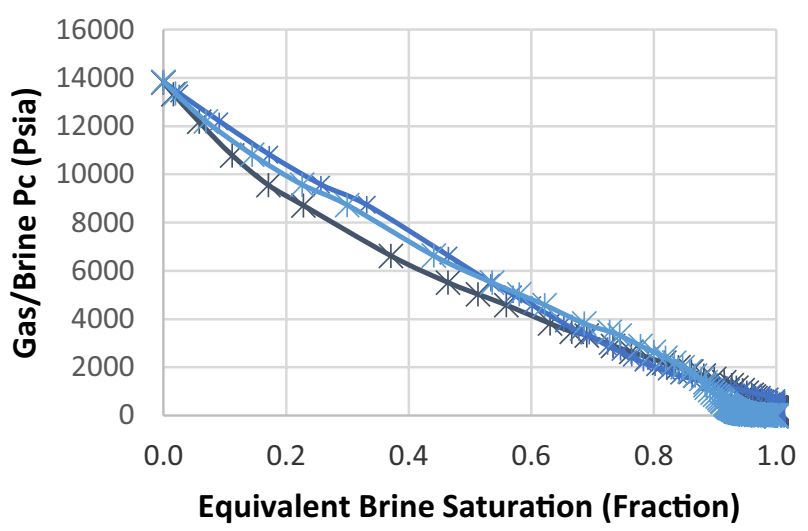

Lithofacies 3 Capillary pressure



Fig. 15 Capillary Pressure and Pore Size Distribution

\section{Surfactant screening}

The sample of 22 surfactants identified for screening was sourced from chemical vendor suppliers. Figure 16 presents
Lithofacies 1 Pore Throat Size Distribution
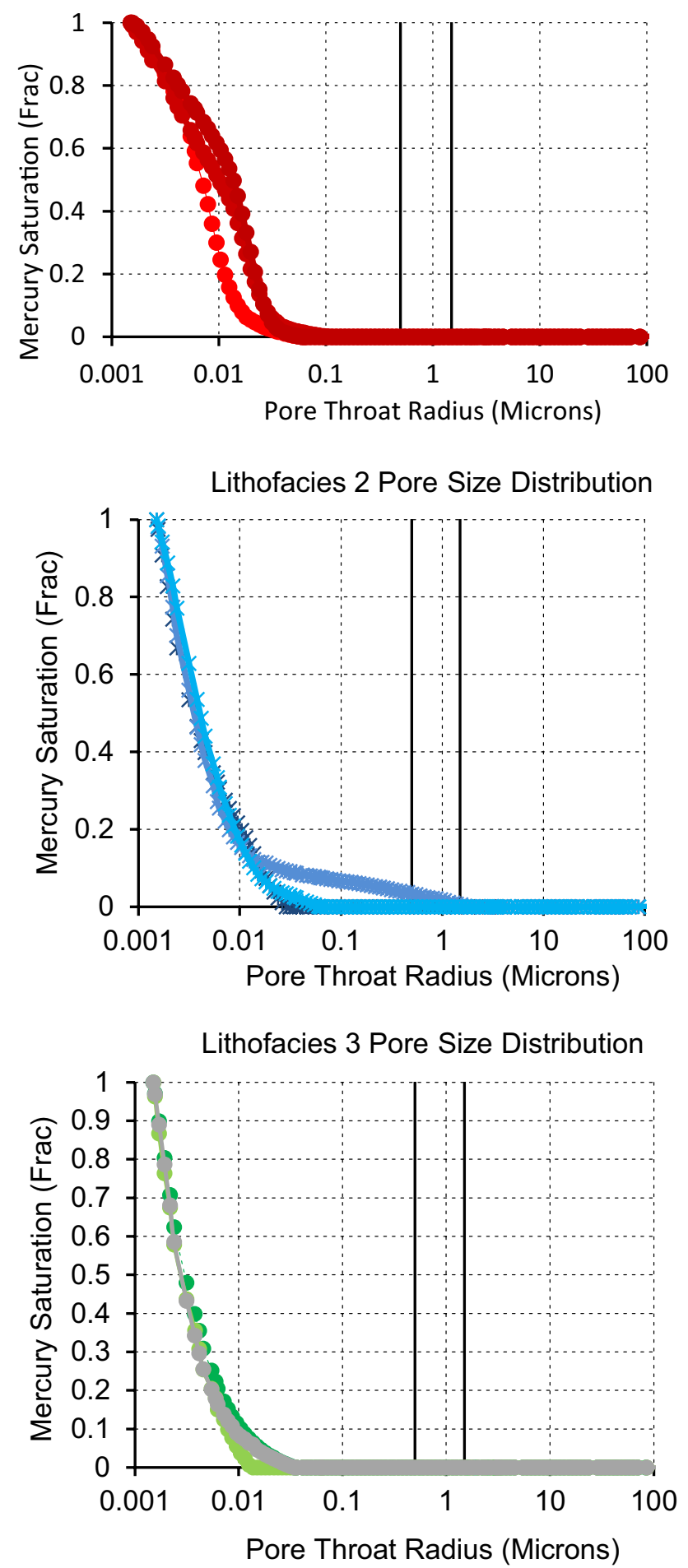

the results for the screening. Three of the surfactants, GlucoPure Wet, SOLOTERRA 938, and Aspiro S2420X, meet the IFT key performance index of less than $0.1 \mathrm{mN} / \mathrm{m}$ and surface tension key performance of less than $28 \mathrm{mN} / \mathrm{m}$. 


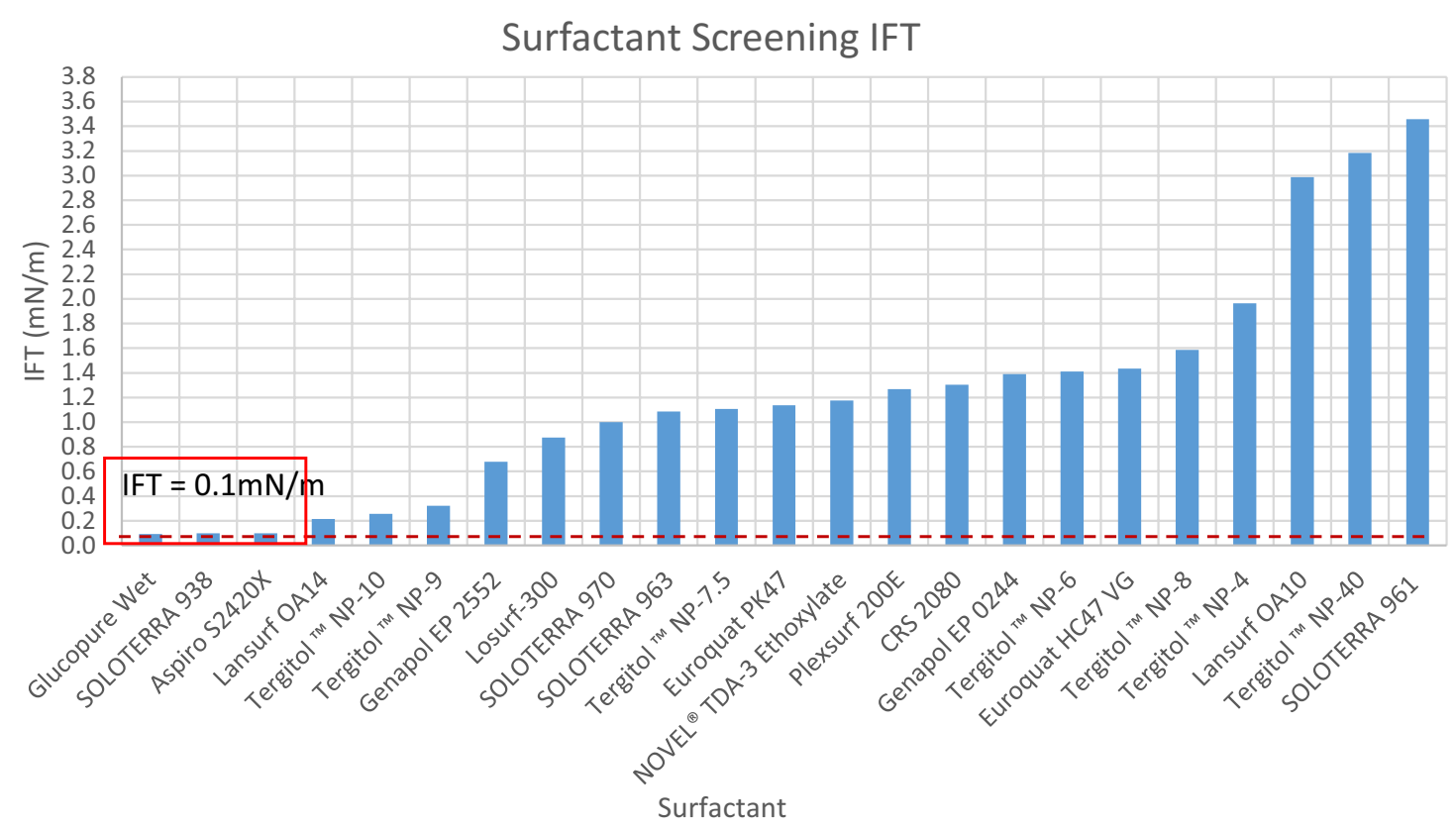

Fig. 16 IFT measurement of 22 Screened Surfactants



Fig. 17 Liquid-liquid IFT for Shortlisted Alternative Surfactants

IFT and surface tension key performance was based on the trends identified from a chemical company survey. The survey results showed the IFT between surfactant and Montney flowback water screening ranges between $0.09 \mathrm{mN} / \mathrm{m}$ and $3.46 \mathrm{mN} / \mathrm{m}$.

\section{Interfacial tension and surface tension}

The 28-day liquid-liquid IFT and surface tension for SOLOTERRA 938, Aspiro S2420X, and GlucoPure Wet were measured. The analysis was conducted for 28 day based on the field implementation duration where fluid-fluid interaction is ranging from 7 to 28 day. Figure 17 and Fig. 18 show that the IFT and surface tension for all surfactants remain unchanged throughout the 28-day stability test at reservoir

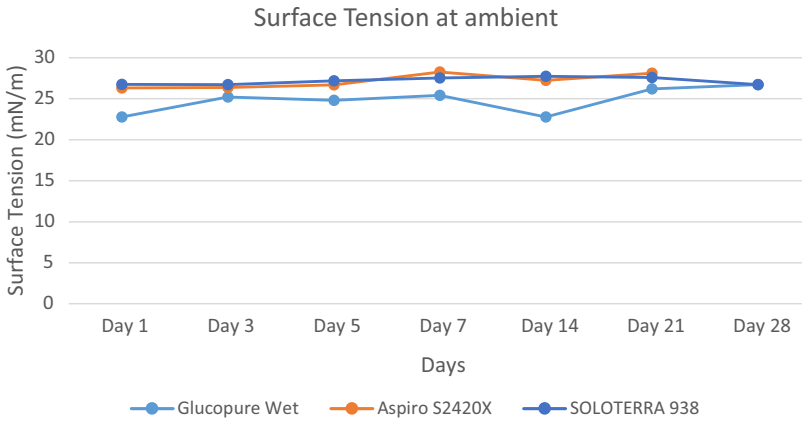

Fig. 18 Surface Tension for Shortlisted Alternative Surfactants

temperature. The 28-day stability test was carried out to determine and eliminate the surfactant degradation factor caused by elevated temperature and interaction duration since surfactant degradation affects its performance (SalahEldin Hussien et al. 2019).

\section{The effect of soaking test with reservoir rock on $\mathrm{pH}$ measurement}

The soaking test was performed on GlucoPure Wet, Aspiro S2420X, and SOLOTERRA 938. The fluids were tested for changes in $\mathrm{pH}$, surface tension, interfacial tension, concentration, and adsorption before and after soaking.

SOLOTERRA 938 (ethoxylated carboxylate) is an anionic surfactant but exhibits non-ionic surfactant properties in an acidic environment. SOLOTERRA 938 is neutralized 
with alkali to form ether carboxylates. According to the Technical Data Sheet (TDS), this surfactant is acidic by nature and has a $\mathrm{pH}$ value of 3 . Internal laboratory measurement showed that SOLOTERRA 938 has a pH of 3.17. Figure 19 shows the change in the $\mathrm{pH}$ values before and after soaking. The $\mathrm{pH}$ for the mixed water is 6.45 , and when SOLOTERRA 938 is diluted in the mixed water, its $\mathrm{pH}$ increased slightly to 3.81 for the pre-soaked fluid. The $\mathrm{pH}$ for lithofacies 1, 2, and 3 increased from 3.81 to 6.37 after seven days of fluid interaction with reservoir rock. In summary, SOLOTERRA 938 behaved as a non-ionic surfactant in the pre-soaked fluid, and its behavior changed to anionic SOLOTERRA 938 after seven days of interaction with the reservoir rock. GlucoPure Wet and Aspiro S2420X did not show significant changes after seven days of interaction with the reservoir rock. This behavior is similar to base water without surfactant.

$\mathrm{pH}$ measurement is critical for $\mathrm{pH}$-sensitive surfactant because surfactant performance varies with $\mathrm{pH}$. SOLOTERRA 938, GlucoPure Wet, and Aspiro S2420X are pHsensitive surfactants, where the measured surface tension of the surfactants varies with $\mathrm{pH}$ value. A solution $\mathrm{pH}$ higher than surface point (zero of charge) is preferred to reduce surfactants adsorption (Zulkifli et al. 2020). Figure 19 shows that the pH for GlucoPure Wet and Aspiro S2420X is stable, but the $\mathrm{pH}$ for SOLOTERRA 938 increased from acidic to neutral after seven days of fluid-rock interaction.

\section{The effect of soaking test on surface tension}

The surface tension of pre-soaking and post-soaking fluids interacting with the rock was measured using the Pendant
Drop tensiometer. Results showed that the surface tension for GlucoPure Wet and Aspiro S2420X increased after seven days of fluid-rock interaction at reservoir pressure and temperature. However, the surface tension for SOLOTERRA 938 decreased slightly after seven days of soaking. Figure 20 and Fig. 21 show that this occurred for both air and hydrocarbon gas.

Table 5 presents the result of SOLOTERRA 938, which is similar to that reported by Chiappisi (2017). The surface tension for polyoxyethylene alkyl ether carboxylic acids decreased with lower concentrations at different $\mathrm{pH}$ values and increased after a specific concentration. In this study, the value for surface tension is influenced by $\mathrm{pH}$ value due to the $\mathrm{pH}$-sensitive surfactant behavior. The surfactant performance varies with $\mathrm{pH}$ value.

\section{The effect of soaking test on IFT}

Figure 22 presents the IFT measurement, which shows that SOLOTERRA 938 retained an IFT of $0.1 \mathrm{mN} / \mathrm{m}$ after seven days of soaking. This indicates that it has a good performance with low interfacial tension at reservoir condition for seven days. Aspiro S2420X showed a minimal increase on IFT from $0.1 \mathrm{mN} / \mathrm{m}$ to $0.14 \mathrm{mN} / \mathrm{m}$ after the soaking test. Aspiro S2420X recorded a low IFT value at a low concentration at the spinning drop tubing. The concentration test using HPLC confirmed that the surfactant was adsorbed on the rock surface. The surfactant adsorption was evident by the reduced surfactant concentration and higher IFT value and surface tension, all of which reduced surfactant efficiency (Belhaj et al. 2020). However, GlucoPure Wet showed a significant loss of performance. The increase in IFT from
Fig. 19 Comparison for Preand Post-soaking Fluids

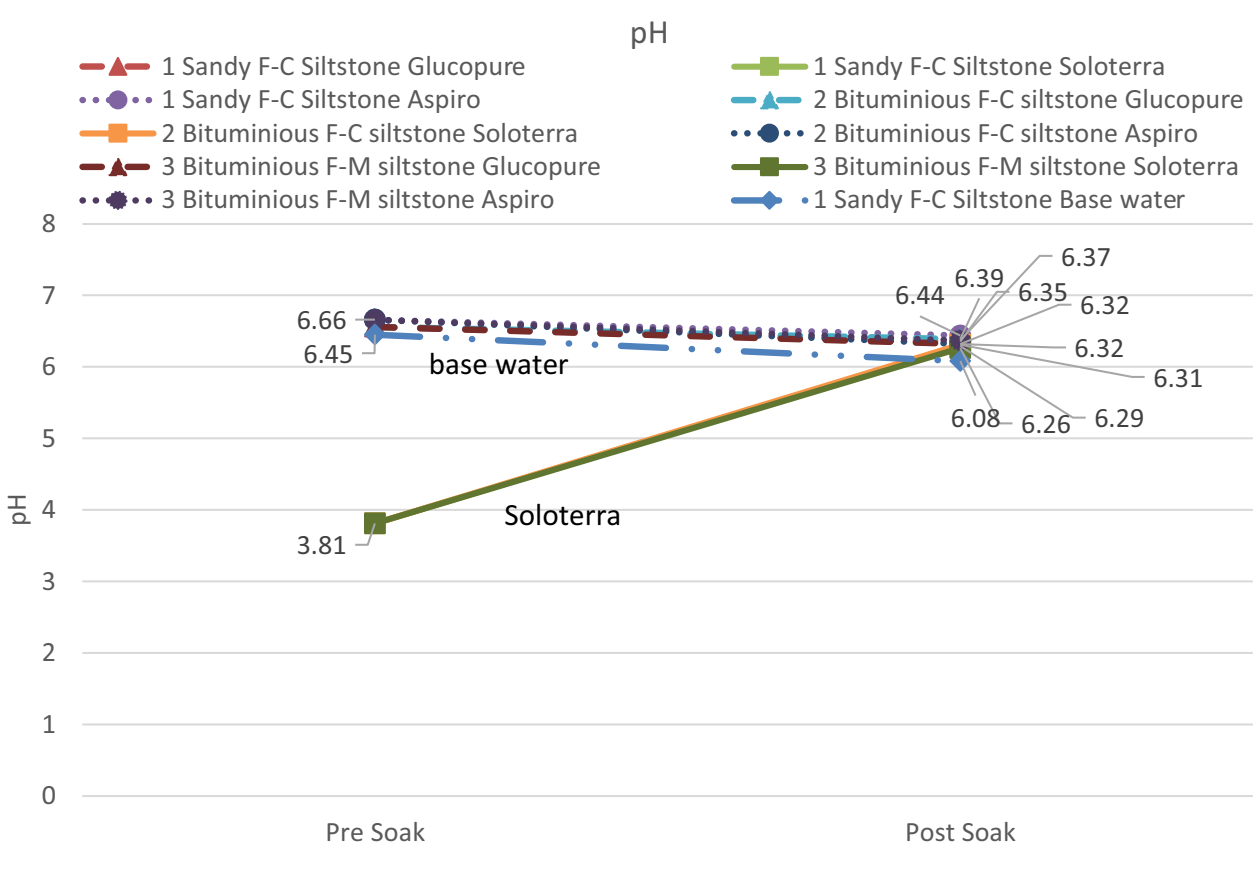


Fig. 20 Pendant Drop Surface Tension with Air at Ambient Condition for Pre- and Postsoaking Fluids

Fig. 21 Pendant Drop Surface Tension with Hydrocarbon Gas at Ambient Condition for Preand Post-soaking Fluids
Pre and Post Soak Surface Tension Pendant Drop with air at ambient
$-\Delta-1$ Sandy F-C Siltstone Glucopure

-..1 1 Sandy F-C Siltstone Aspiro

2 Bituminious F-C siltstone Soloterra

- $\mathbf{\Delta}$ - 3 Bituminious F-M siltstone Glucopure

. 03 Bituminious F-M siltstone Aspiro

33
-1 Sandy F-C Siltstone Soloterra

$-\Delta-2$ Bituminious F-C siltstone Glucopure

...2 2 Bituminious F-C siltstone Aspiro

$\longrightarrow 3$ Bituminious F-M siltstone Soloterra

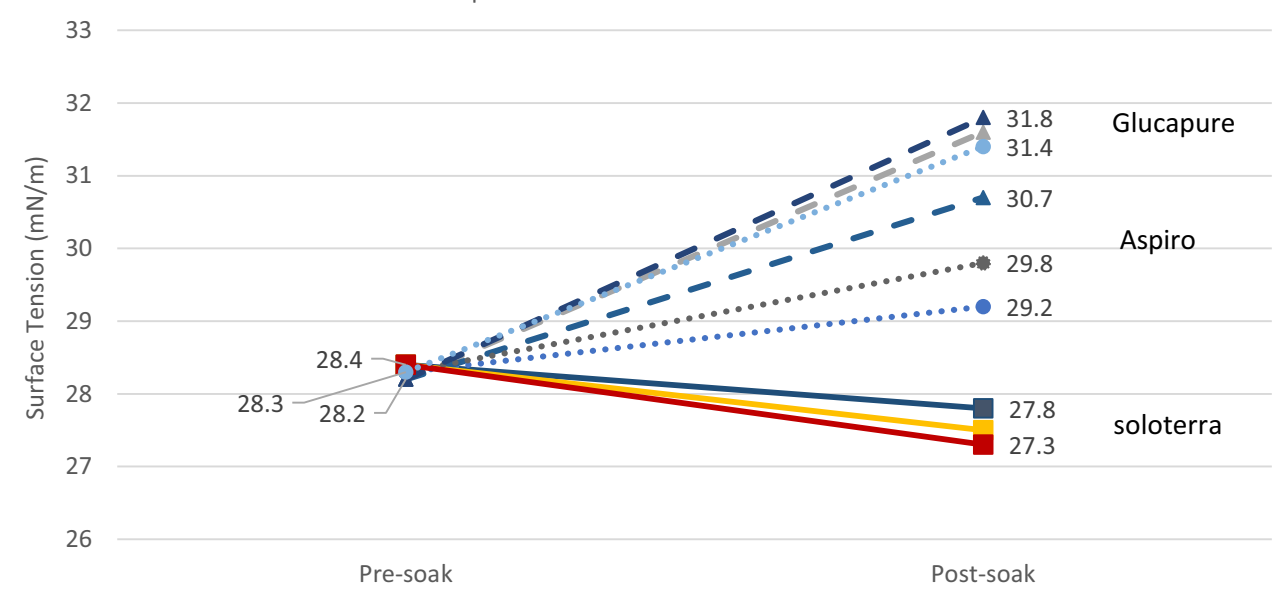

Pre and Post Soak Surface Tension Pendant Drop with HC gas at ambient

$-\triangle-1$ Sandy F-C Siltstone Glucopure

... 1 Sandy F-C Siltstone Aspiro

2 Bituminious F-C siltstone Soloterra

- 3 Bituminious F-M siltstone Glucopure

... 3 Bituminious F-M siltstone Aspiro

30

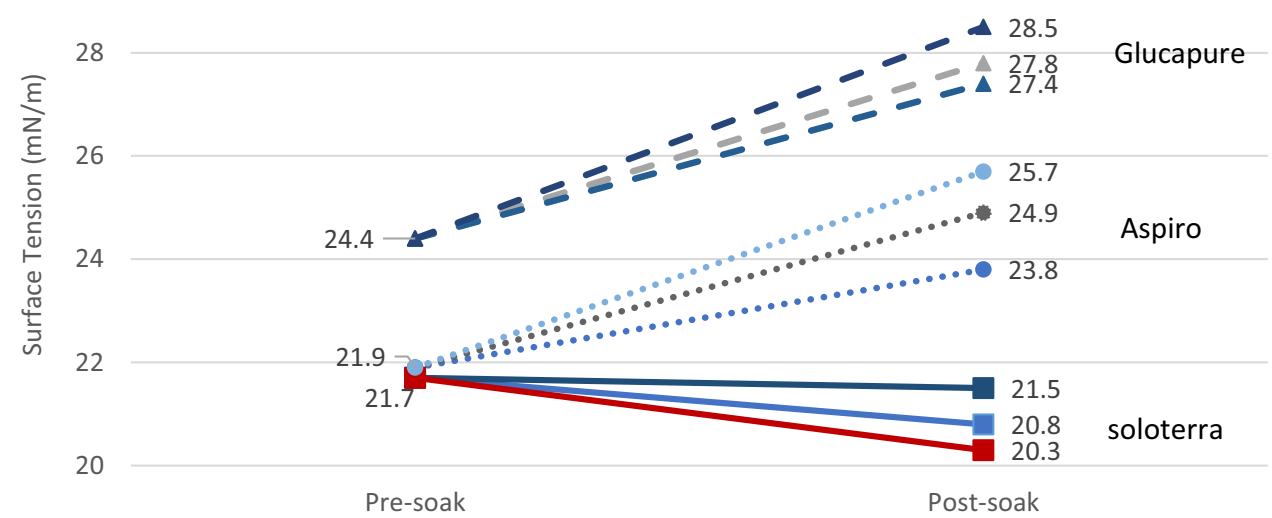

-1 Sandy F-C Siltstone Soloterra
-

-..2 2 Bituminious F-C siltstone Aspiro

- 3 Bituminious F-M siltstone Soloterra
Table 5 Summary of Pre- and Post-soaking Fluids Tests of SOLOTERRA 938

\begin{tabular}{lcl}
\hline Parameter & Pre-soaking & Post-soaking \\
\hline Concentration (wt \%) & 0.1 & 0.088 \\
$\mathrm{pH}$ & 3.81 & 6.31 \\
Surface tension with air (mN/m) & 28.4 & 27.5 \\
Surface tension with hydrocarbon & 21.7 & 20.8 \\
$\quad$ gas $(\mathrm{mN} / \mathrm{m})$ & & \\
\hline
\end{tabular}

0.003 to $0.15 \mathrm{mN} / \mathrm{m}$ and the loss of $34 \%$ to $38.8 \%$ surfactant concentration indicate surfactant adsorption.

\section{The effect of soaking test on concentration and adsorption measurement}

High-performance liquid chromatography (HPLC) was used to measure the active concentration in the pre-soaking and 
Fig. 22 IFT for Pre- and Postsoaking Test Fluids
Pre and Post Soaking Test (Liquid-liquid IFT)



HPLC Concentration on Pre and Post Soaking test Fluids



Fig. 23 Concentration Comparison of Pre- and Post-soaking Test Fluids post-soaking test solution. The concentration was used as an input in surfactant adsorption calculation. The general understanding is that the adsorption of charged surfactant onto a surface is due to the cation exchange mechanism.

Figure 23 and Fig. 24 show the changes in concentration and adsorption. Aspiro S2420X showed the highest concentration loss after seven days of soaking with the reservoir rock. The concentration loss ranged from 57 to $81 \%$ and contributed to the high adsorption that ranges from 2.043 to $2.903 \mathrm{mg} / \mathrm{g}$ rock. This type of surfactant is not suitable for the Montney shale formation. The $\mathrm{pH}$ value affects the adsorption level. GlucoPure Wet has a low concentration loss of between $34 \%$ and $38.8 \%$, which results in low adsorption of 1.219 to $1.391 \mathrm{mg} / \mathrm{g}$ rock. However, the increasing IFT and surface tension values make this type of surfactant unsuitable for Montney shale formation. The loss of SOLOTERRA 938 concentration is minimal and ranges between 12 and $27 \%$, while its adsorption value ranges between 0.43 and $0.968 \mathrm{mg} / \mathrm{g}$ rock. Based on the data, SOLOTERRA 938 shows good surfactant performance efficiency for Montney shale formation and condition.

$\mathrm{pH}$ is one of the key factors affecting adsorption, especially for $\mathrm{pH}$-sensitive surfactants since surfactant performance varies with $\mathrm{pH}$ value. SOLOTERRA 938, GlucoPure Wet, and Aspiro S2420X are pH-sensitive surfactants. The pH of GlucoPure Wet and Aspiro S2420X did not vary for pre-soaking and post-soaking test fluids. The adsorption performance of these surfactants is not influenced by $\mathrm{pH}$ but is due to cation exchange. 
Fig. 24 Adsorption Comparison of Pre- and Post-soaking Test Fluids
Adsorption

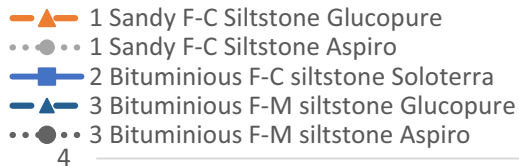

$-\Delta-1$ Sandy F-C Siltstone Glucopure

-. 1 Sandy F-C Siltstone Aspiro

-2 Bituminious F-C siltstone Soloterra

- 3 Bituminious F-M siltstone Glucopure

... 3 Bituminious F-M siltstone Aspiro

-1 Sandy F-C Siltstone Soloterra

- -2 Bituminious F-C siltstone Glucopure

... 2 Bituminious F-C siltstone Aspiro

3 Bituminious F-M siltstone Soloterra

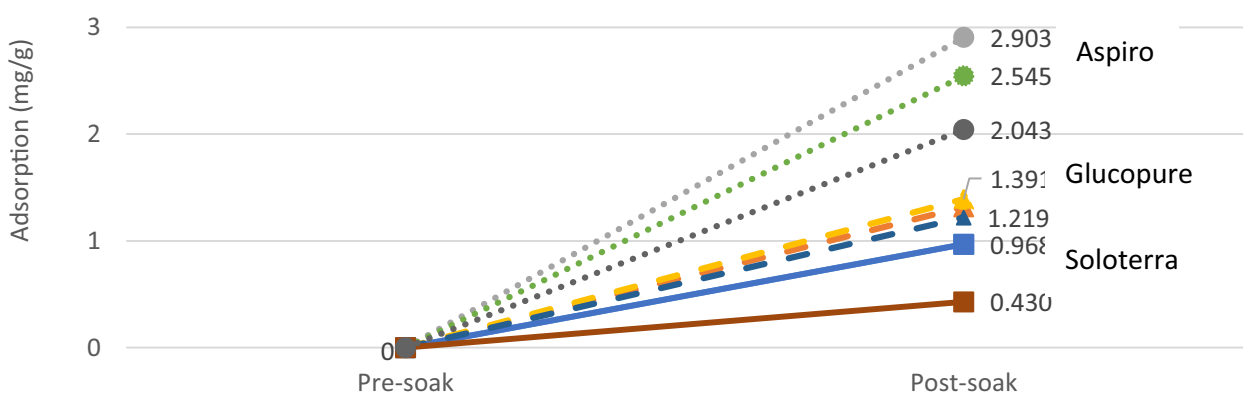

The $\mathrm{pH}$ for SOLOTERRA 938 increased from 3.81 to 6.37. SOLOTERRA 938 is an anionic surfactant although it has the typical properties of a non-ionic surfactant in an acidic environment. SOLOTERRA 938 behaved as a nonionic surfactant during the pre-soaking test and changed its behavior to anionic surfactant after seven days of interaction with reservoir rock. The adsorption occurred during the early stage of soaking due to the non-ionic behavior of SOLOTERRA 938 at a $\mathrm{pH}$ of 3.81, where it was adsorbed on the rock surface through the cation exchange mechanism. Acetic acid has the same nature as SOLOTERRA 938 and may have free ions that attack the rock surface charges due to the dipole interaction and cause the fluid to be neutralized during the seven-day soaking period. This mechanism does not affect surfactant adsorption and concentration. Chiappisi (2017) recorded a lower activity coefficient of surfactant, which resulted in minimum surface tension at high $\mathrm{pH}$, as observed in this study.

\section{Conclusion}

An assessment of 22 surfactants showed that ethoxylated carboxylate is the suitable surfactant for Montney shale formation because

- The IFT remained $0.1 \mathrm{mN} / \mathrm{m}$ after seven days of interaction with the reservoir rock.

- The surface tension remained unchanged after seven days of interaction with the reservoir rock with both air and hydrocarbon gas at ambient temperature.

- The loss of surfactant concentration is $12 \%$ after seven days of interaction with the reservoir rock (from 0.1 to $0.088 \mathrm{wt} \%)$.
- The adsorption value is low and ranges between 0.43 and $0.968 \mathrm{mg} / \mathrm{g}$ rock.

Acknowledgment The authors would like to acknowledge PETRONAS and UTP (Grant No: 015MD0-009) for the permission to publish this paper and to Dr Tan Chee Phuat, Dr Raj Deo Tewari, Fakharudin Che Yusof, and Normawati Samsodin for their technical assistance.

Funding This study was supported by PETRONAS and Universiti Teknologi PETRONAS (Grant No: 015MD0-009).

\section{Declarations}

Conflict of interest On behalf of all the co-authors, the corresponding author states that there is no conflict of interest.

Open Access This article is licensed under a Creative Commons Attribution 4.0 International License, which permits use, sharing, adaptation, distribution and reproduction in any medium or format, as long as you give appropriate credit to the original author(s) and the source, provide a link to the Creative Commons licence, and indicate if changes were made. The images or other third party material in this article are included in the article's Creative Commons licence, unless indicated otherwise in a credit line to the material. If material is not included in the article's Creative Commons licence and your intended use is not permitted by statutory regulation or exceeds the permitted use, you will need to obtain permission directly from the copyright holder. To view a copy of this licence, visit http://creativecommons.org/licenses/by/4.0/.

\section{References}

Amirianshoja T et al (2013) A comparative study of surfactant adsorption by clay minerals. J Pet Sci Eng Elsevier 101:21-27. https:// doi.org/10.1016/j.petrol.2012.10.002

Barati R, Liang JT (2014) A review of fracturing fluid systems used for hydraulic fracturing of oil and gas wells'. J Appl Polym Sci. https://doi.org/10.1002/app.40735 
Belhaj AF et al (2020) The effect of surfactant concentration, salinity, temperature, and $\mathrm{pH}$ on surfactant adsorption for chemical enhanced oil recovery: a review. J Pet Explor Prod Technol. https://doi.org/10.1007/s13202-019-0685-y

Chai Y, Li X, Jing D (2019) Oil \& Gas research application of surfactants in hydraulic fracturing for enhanced. Oil Gas Recovery 5(1):1-10. https://doi.org/10.4172/2472-0518.1000161

Chiappisi L (2017) Polyoxyethylene alkyl ether carboxylic acids: an overview of a neglected class of surfactants with multiresponsive properties. Adv Colloid Interface Sci Elsevier 250:79-94. https:// doi.org/10.1016/j.cis.2017.10.001

Ferrer I, Thurman EM (2015) Chemical constituents and analytical approaches for hydraulic fracturing waters. Trends Environ Anal Chem Elsevier 5:18-25. https://doi.org/10.1016/j.teac.2015.01. 003

Fichter J, et al. (2010) AADE-10-DF-HO-08 critical considerations for successful hydraulic fracturing and shale gas recovery

Fink JK (2013) Hydraulic fracturing chemicals and fluids technology hydraulic fracturing chemicals and fluids technology. J Pet Sci Eng. https://doi.org/10.1016/C2012-0-02544-6

Ghanbari E, Dehghanpour H (2016) The fate of fracturing water: a field and simulation study. Fuel Elsevier 163:282-294. https://doi.org/ 10.1016/j.fuel.2015.09.040

Gharibi A, Zoveidavianpoor M (2015) Akademia Baru hydraulic fracturing for improved oil recovery Akademia Baru. J Adv Res Fluid Mech Therm Sci ISSN 9(1):1-18

Hall, B. J. and Govert, A. (2016) 'Techniques for using core CT data for facies identification and analysis', SPE/AAPG/SEG Unconventional Resources Technology Conference, (September).

Han Z et al (2015) Physicochemical properties and phase behavior of Didecyldimethylammonium Chloride/Alkyl Polyglycoside surfactant mixtures. J Surfactants Deterg 18(4):641-649. https:// doi.org/10.1007/s11743-015-1679-5

$\mathrm{He} \mathrm{K}$ et al (2015) 'Journal of petroleum science and engineering evaluation of surfactant performance in fracturing fl uids for enhanced well productivity in unconventional reservoirs using Rock-on-aChip approach. J Pet Sciand Eng Elsevier 135:531-541. https:// doi.org/10.1016/j.petrol.2015.10.008

Heyob KM et al (2017) 'Natural Attenuation of Nonionic Surfactants Used in Hydraulic Fracturing Fluids : Degradation Rates. Pathways, and Mechanisms Natural Attenuation of Nonionic Surfactants Used in Hydraulic Fracturing Fluids : Degradation'. https://doi.org/10.1021/acs.est.7b01539

Huggett JM (1992) Petrography, mineralogy and diagenesis of overpressured tertiary and late cretaceous mudrocks from the East Shetland Basin. Clay Miner 27(4):487-506

Javaheri A et al (2018) Imbibition oil recovery from tight rocks with dual-wettability behavior. J Petrol Sci Eng 167:180-191. https:// doi.org/10.1016/j.petrol.2018.01.046

Kaufman, P., Penny, G. S. and Paktinat, J. (2008) 'Critical evaluations of additives used in shale slickwater fracs', in Society of Petroleum Engineers - Shale Gas Production Conference 2008.

Li, N. et al. (2013) 'A multiple-continuum model for simulation of gas production from shale gas reservoirs', Society of Petroleum Engineers - SPE Reservoir Characterisation and Simulation Conference and Exhibition, RCSC 2013: New Approaches in Characterisation and Modelling of Complex Reservoirs, 1(September 2013), pp. 542-554. doi: https://doi.org/10.2118/165991-MS.

Liang T et al (2020) Evaluating the Performance of Surfactants in Enhancing Flowback and Permeability after Hydraulic Fracturing through a Microfluidic Model. SPE J 25(1):268-287. https://doi. org/10.2118/199346-PA

Liu Q et al (2004) Improved oil recovery by adsorption-desorption in chemical flooding. J Petrol Sci Eng. https://doi.org/10.1016/j. petrol.2003.12.017
Lu, B. (2016) 'Evaluation of physico-chemical properties of biorefinery-derived amphiphilic molecules and their effects on multi-scale biological models HAL Id : tel-01299523 Thèse présentée pour 1 ' obtention du grade de Docteur de 1 ' UTC'.

$\mathrm{Lu} \mathrm{Y}$ et al (2018) Reasons for the low flowback rates of fracturing fluids in marine shale. Natural Gas Industry B. https://doi.org/10. 1016/j.ngib.2017.11.006

Michael W. Smith and John M.Terracina (2006) ‘US20060289165A1. pdf'.

Mirchi V et al (2015) Dynamic interfacial tension and wettability of shale in the presence of surfactants at reservoir conditions. Fuel. https://doi.org/10.1016/j.fuel.2015.01.077

Moiré, M. et al. (2016) 'A new microfluidic tensiometer for optimizing EOR formulations', in Proceedings - SPE Symposium on Improved Oil Recovery.

Muherei MA, Junin R (2009) Equilibrium Adsorption Isotherms of Anionic, Nonionic Surfactants and Their Mixtures to Shale and Sandstone. Modern Applied Science. https://doi.org/10.5539/mas. v3n2p158

Nickel D et al (2007) Interfacial properties of surfactant mixtures with alkyl polyglycosides. Trends in Colloid and Interface Science VI 252:249-252. https://doi.org/10.1007/bfb0116322

Penny, G., Pursley, J. T. and Holcomb, D. (2005) 'The application of microemulsion additives in drilling and stimulation results in enhanced gas production', in SPE Production and Operations Symposium, Proceedings. doi: https://doi.org/10.2523/94274-ms.

Rabie A, Zhou J, Qu Q (2019) 'Evaluation of a new environmentally friendly flowback surfactant and its application to enhance oil and gas productivity', in SPE Middle East Oil and Gas Show and Conference. MEOS, Proceedings. https://doi.org/10.2118/195045-ms

Rapp BE (2017) 'Measuring Surface Tension and Free Surface Energy', in Microfluidics: Modelling. Mechanics and Mathematics. https:// doi.org/10.1016/b978-1-4557-3141-1.50022-8

SalahEldin Hussien O et al (2019) Experimental study on the use of surfactant as a fracking fluid additive for improving shale gas productivity. J Pet Sci Eng Elsevier BV 183:106426. https://doi. org/10.1016/j.petrol.2019.106426

Stauffer CE (1965) The measurement of surface tension by the pendant drop technique. J Phys Chem. https://doi.org/10.1021/j1008 $90 \mathrm{a} 024$

Sterpenich J et al (2009) 'Experimental ageing of oolitic limestones under $\mathrm{CO} 2$ storage conditions petrographical and chemical evidence. Chem Geol. https://doi.org/10.1016/j.chemgeo.2009.04. 011

Sulek MW, Wasilewski T (2009) Influence of critical micelle concentration (CMC) on tribological properties of aqueous solutions of alkyl polyglucosides. Tribol Trans 52(1):12-20. https://doi.org/ 10.1080/10402000801911879

Sun, Y. (2014) Impact of slickwater fracturing fluid compositions on the petrophysical properties of shale and tightsand.

Tadros TF (2010) Chapter physical chemistry of surfactant solutions. In: Tadros TF (ed) Colloids and Interface Science Series. WILEYVCH Verlag GmbH \& Co. KGaA, Weinheim. https://doi.org/10. 1002/9783527631193.ch55

Vonnegut B (1942) Rotating bubble method for the determination of surface and interfacial tensions. Rev Sci Instrum. https://doi.org/ $10.1063 / 1.1769937$

Warwel S et al (2001) Surfactants from glucamines and $\omega$-epoxy fatty acid esters. Eur J Lipid Sci Technol 103(10):645-654. https://doi. org/10.1002/1438-9312(200110)103:10\%3c645::AID-EJLT645\% 3e3.0.CO;2-0

Wu Y et al (2010) Branched alkyl alcohol propoxylated sulfate surfactants for improved oil recovery. Tenside Surfactants Deterg. https://doi.org/10.3139/113.110064

Yaich E et al (2015) 'A case study: the impact of soaking on well performance in the marcellus', in society of petroleum 
engineers-unconventional resources technology conference. URTeC 2015. https://doi.org/10.2118/178614-ms

Yue $\mathrm{Z}$ et al. (2016) Multifunctional fracturing additives as flowback AIDS. In Proceedings - SPE Annual Technical Conference and Exhibition. doi: https://doi.org/10.2118/181383-ms.

Zhang J et al. (2010) Development and field pilot test of a novel viscoelastic anionic-surfactant (VAS) fracturing fluid. In Society of Petroleum Engineers Western North American Regional Meeting 2010 - In Collaboration with the Joint Meetings of the Pacific Section AAPG and Cordilleran Section GSA.
Zulkifli NN et al (2020) Evaluation of new surfactants for enhanced oil recovery applications in high-temperature reservoirs. J Pet Explor Prod Technol. https://doi.org/10.1007/s13202-019-0713-y

Publisher's Note Springer Nature remains neutral with regard to jurisdictional claims in published maps and institutional affiliations. 